\title{
Digital Citizenship and Activism: Questions of Power and Participation Online
}

\author{
Dr. Maria Bakardjieva*, Dr. Jakob Svensson**, \\ Dr. Marko M. Skoric*** \\ *University of Calgary, Canada, mpbakardjieva@gmail.com \\ **Karstand University, Sweden, Jakob.Svensson@kau.se \\ *** Nanyang Technological University, Singapore, marko@ntu.edu.sg
}

Abstract: The eJournal of eDemocracy and Open Government (JeDEM) is a peer-reviewed, Open Access journal (ISSN: 2075-9517) published twice a year. It addresses theory and practice in the areas of eDemocracy and Open Government as well as eGovernment, eParticipation, and eSociety. JeDEM publishes ongoing and completed research, case studies and project descriptions that are selected after a rigorous blind review by experts in the field.

More information: www.jedem.org

Acknowledgement: I would like to thank my Master students Oliver Coronel, Manuela Diethelm, Corina Frueh, and Karoline Lässer for contributing to the state-of-the art and conducting expert interviews.

$\mathrm{T}$

he long-raging debate over the potential of the Internet and new media to invigorate citizens' participation in politics is not a matter of theoretical speculation any more but an acutely practical affair. Nowadays, when citizens, activists and participants in social movements want to voice their views and define their political identities they increasingly do so in hybrid media environments. Slowly but surely, these environments exhibit exciting new possibilities for mobilization, organization and discussion. With a massive growth in online social networking, digital infrastructures offer citizens new channels for speaking and acting together and thus lower the threshold for involvement in collective action and, eventually, politics. This, in turn, changes the power dynamics of participation. Digital storytelling, for example, is a novel tool for engaging ordinary people in the discussion of issues of wide public significance. Mass media and institutional gatekeepers are being circumvented by citizen reporters and commentators who provide first-hand, real-time coverage and non-hegemonic interpretations of offline political events. This increases pressure on traditional media organizations to include different voices originating from social media platforms, further enhancing their reach and impact. 
However, some observers have questioned the notion of new media as tools for social change as well as their capacity to level the political playing field. These critical views have been voiced specifically with regards to the implications of corporate ownership of social media platforms and the increasing capacity of governments to monitor citizens' behavior. Another question that has been raised is whether 'clicktivism' is eroding the physical or embodied participation constituting traditional offline activism. Doubts have been voiced also about the possibility of political causes succeeding through mediated activism alone.

The rise of social media has also prompted many political institutions and actors to reexamine not only their media strategies, but more importantly, their ways of governance. Looking from the top down, some states, municipalities and governmental organizations have been at pains to make use of new media in fulfilling their mandates. They have strived to build new openness and accessibility into their existing practices. To what extent have these efforts resonated with citizens' expectations and demands? Have they connected with the bottom-up impulses and trends described previously? Have they contributed to enhancing citizens' participation in making the decisions that affect their lives? What uncertainties and challenges does this situation present?

The contributions to this special issue engage with these debates head-on but also reach further, to the practical question of how, through what technical means and social arrangements, can the affordances of new media be mobilized in empowering and effective civic action. They present actual cases of such mobilization in living detail and extract from them observations, tips, and principles of design and organization that can be carried over to other similar situations across the field. It would be a simplification to say that thanks to these insights the big questions raised in the literature find definitive answers. They remain open and vexing for researchers and activists alike. However, the studies reported here help anchor these questions in concrete social contexts, technical platforms and actor experiences. In this way, new dimensions of the issues are revealed and some unexpected possibilities and pitfalls are detected. The articles cover local developments as well as transnational civic activism, grassroots initiatives as well as projects pursued by administrative bodies. They delineate successful tactics invented by grassroots movements alongside with new incarnations of powerful discourses in digital formats.

The study by Henrik Serup Christensen starts us on a cautiously optimistic note by showing through analysis of survey data gathered in Finland that people who regularly engage in political activities online are no less informed and politically engaged offline than those who turn to the Internet for political reasons less frequently. Christensen interprets these results as a proof that fears of "Internet slacktivism" replacing embodied participation in the political sphere are overstated. While politics performed on the Internet may not be the remedy for all ills of contemporary democracies, it does not inhibit those who are interested from getting involved in political activities offline as some pessimistic accounts have predicted. 
Yana Breindl's in-depth examination of the practices of a varied set of European "digital rights" activist groups traces the interconnections of their online and offline activities and demonstrates both the importance and the complexity of translating the decisions reached in digital forums to the actual world of political institutions. Interestingly, Breindl's close scrutiny of how digital activism actually works reveals a number of exclusions and systematic inequalities embedded in the process. With respect to the particular cause mobilizing these activists, the ability to participate as well as the chance to emerge as a leader is strongly dependent on technical competence, belonging to geek culture, being male, highly educated and urban.

Paul Hepburn's fascinating network ethnography of a public debate around a referendum on a proposed measure for reducing traffic congestion in Manchester reveals in vivid colors that the online sphere is highly contested among various agents and infiltrated by powerful interests just like the traditional media space. His research discerns effective tactics implemented by citizens participating in the debate allowing them to shrewdly navigate and shape the online public opinion and ultimately influence the outcome of the referendum. At the same time it also becomes clear that the coalition of powerful business and political players representing one of the sides in the debate manages to earn prominence in the digital sphere through massive investment of resources, professional appeal and multimedia pressure. Hepburn then offers interesting reflections on where that leaves us on the question of power equalization versus imbalance in online participation.

The next contribution by Roy Bendor, Susanna Haas Lyons and John Robinson offers another colorful example of e-deliberation concerning sustainable transportation staged in the city of Vancouver, Canada. The authors' analysis delves into the different modes of discourse comprising democratic deliberation and its complexities. It zooms in on the technical features of digital platforms, in particular Facebook, and the ways in which they support or obstruct desired processes inherent to such deliberation. They find that Facebook's design is biased towards a dialogical, open-ended mode of discourse, allowing participants to integrate various styles of expression, personal experiences and forms of reasoning. However, it hinders decision-making and the achievement of consensus. Bendor et al. identify adjustments that need to be made to the Facebook platform and moderation strategies that would allow shared understanding, agreement and concerted action to emerge as a result of public deliberation. Thus the close examination of the Vancouver experience generates useful ideas that can help future initiatives aimed at involving ordinary citizens in the discussion of initiatives planned by administrative and other political bodies.

A very different kind of discourse and a distinct relationship between those in power and ordinary citizens is the object of discussion in the article by Patrícia Dias da Silva and José Luís Garcia. The authors' goal is to determine the democratic value of satirical memes propagated via online social networks. The particular meme in question in their study is 
the "Downfall meme," a common pattern of ridiculing powerful personalities based on a scene of the film Der Untergang that proliferated across numerous YouTube videos. The authors suggest that although in such activities citizens do not intend any direct political message or effect, their creative power unlocked by new media effectively brings into existence an oppositional stream in popular and political culture. They use historical and literary evidence to reinforce the importance of humorous expression as a form of cultural activism that challenges the established authorities and political order.

In the final article of this collection, our attention is directed to an example of a concrete digitally supported campaign, addressing the need to bring citizens and municipal decision-makers closer together. Edith Maier offers a blueprint, informed by the principles of behavioral economics, for engaging citizens in the creation and implementation of policies aimed at promoting sustainable local mobility in the City of St. Gallen, Switzerland. Taking into account the specificities of the Swiss democratic system (i.e. direct democracy), the project outlines a strategy incorporating both social media and open data approaches and goes beyond the usual e-participation goals of consultation and legitimization.

Across the diverse array of cases portrayed in these studies the abstract queries about the democratic potential of the Internet and new media suddenly acquire flesh, blood, interfaces and breath-taking dynamics. Clearly, it is not possible and useful to look for an overarching resolution to the argument between optimists and critics. The optimist seeing possibilities and the critic aware of pitfalls instead need to be present on every concrete site and in every instance where digital media and civic and political action meet, mesh and target a concrete goal.

\section{About the Authors}

\section{Dr. Maria Bakardjieva}

Maria Bakardjieva is Professor in the Department of Communication and Culture, University of Calgary, Canada. She is the author of Internet Society: The Internet in Everyday Life (2005, Sage). Currently, Maria is the editor-in-chief of the Journal of Computer-Mediated Communication. Her research has examined Internet use practices across different social and cultural context with a focus on the ways in which users understand and actively appropriate new media. Her current projects look at the interactions between traditional and new media with a view to identifying opportunities for citizen participation in the public sphere.

\section{Dr. Jakob Svensson}

Born August 22, 1965, Sweden, Professor, Institute for International Economic Studies, Stockholm University, 2007; Deputy Director, Institute for International Economic Studies, Stockholm University, 2010

\section{Dr. Marko M. Skoric}

Marko M. Skoric is an assistant professor at the Wee Kim Wee School of Communication and Information, Nanyang Technological University, Singapore. He holds a Ph.D. in Communication from the University of Michigan, and a B.Sc. in Psychology from the University College London, 
UK. Marko's teaching and research interests are focused on new media and social change, with particular emphasis on civic and political implications of new communication technologies. 